\title{
Prognostic significance of CD44 in human colon cancer and gastric cancer: Evidence from bioinformatic analyses
}

\author{
Pu Xia ${ }^{1}$, Xiao-Yan Xu \\ ${ }^{1}$ Department of Cell Biology, College of Basic Medical Science, Liaoning Medical University, Jinzhou, Liaoning, P.R. China \\ ${ }^{2}$ Department of Pathophysiology, College of Basic Medical Science, China Medical University, Shenyang, Liaoning, P.R. China \\ Correspondence to: Pu Xia, email: nn001007@163.com
}

Keywords: CD44, The Cancer Genome Atlas, gastric cancer, colon cancer, bioinformatic analyses

Received: May 06, 2016

Accepted: May 29, 2016

Published: June 14, 2016

\begin{abstract}
CD44 is a well-recognized stem cell biomarker expressed in colon and gastric cancer. In order to identify whether CD44 mRNA could be used as a prognostic marker in colon and gastric cancer, bioinformatic analyses were used in this study. cBioPortal analysis and COSMIC analysis were used to explore the CD44 mutation. CD44 mRNA levels were evaluated by using SAGE Genie tools and Oncomine analysis. Kaplan-Meier Plotter was performed to identify the prognostic roles of CD44 mRNA in these two cancers. In this study, first, we found that low alteration frequency of CD44 mRNA in colon and gastric cancer. Second, the high CD44 mRNA level was found in colon and gastric cancer, and it correlated with a benign survival rate in gastric cancer. Third, CD4 and CD74 may be used as markers to predict the prognosis of colon and gastric cancer. However, the deep mechanism(s) of these results remains unclear, further studies have to be performed in the future.
\end{abstract}

\section{INTRODUCTION}

Cancer has become a major health problem and a large economic burden in China [1]. According to the data of The National Central Cancer Registry of China (NCCR), gastric cancer and colorectal cancer are two commonly diagnosed cancers in both man and women in china [1].

In recent studies, cancer stem cell (CSC) hypothesis has been proposed to explain the pathogenesis of cancers [2]. To understand the exact biological features of CSC, the key thing is to isolate CSC from cancer cells. A series of new studies indicated that CD44 expression was elevated in cancer stem-like cells in many kinds of cancer [3]. The human CD44 gene is located on chromosome 11 p13 [4]. CD44 protein was initially identified as the receptor for hyaluronic acid (HA), and involved in proliferation, differentiation and motility of both normal and cancer cells [5]. CD44 protein contains an $\mathrm{N}$-terminal HA-binding link-homology module, stem region, transmembrane domain, and short C-terminal cytoplasmic domain (Figure 1A) [6]. CD44 isoforms are generated by alternative splicing of 10 variant exons (v1-v10) in the extracellular domain [7]. Molecular weight of CD44 isoforms ranges from $85 \mathrm{kDa}$ (CD44s, standard version) to $250 \mathrm{kDa}$ (CD44 v3-v10) (Supplementary Figure S1) [8].

Following the identification of various CD44 transcripts (Figure 1B and Supplementary Table S1), the studies for CD44 became complex. For example, CD44s suppresses metastasis, but CD44v7-10 facilitates invasion in prostate cancer [9]. CD44 expression in the colon cancer tissue was substantially higher than that in normal mucosa and it correlates with cancer progression and aggressiveness [10]. CD44 expression was positively correlated with lymph node and distant metastasis, and poorer outcome of gastric cancer patients [11]. In this study, we evaluated the significance of CD44 mRNA in human colon and gastric cancer by using The Cancer Genome Atlas (TCGA) data portal.

\section{RESULTS}

CD44 mutation in colon and gastric cancers

The pie chart that included the information of mutations of substitution missense, nonsense, synonymous, and insertion frame shift was generated by using COSMIC. Substitution missense rate is $63.64 \%$ 
and substitution synonymous rate is $36.36 \%$ of mutant samples of colon cancer (Figure 2A). Mutant samples of gastric cancer have $52.94 \%$ substitution missense, $23.53 \%$ substitution synonymous, and $11.76 \%$ deletion frameshift (Figure 2A). Colon cancer has 36.36\% C $>\mathrm{T}$ and $36.36 \%$ $\mathrm{G}>$ A mutation in CD44 coding strand, and $23.08 \% \mathrm{C}>\mathrm{T}$ and $23.08 \% \mathrm{~T}>\mathrm{C}$ mutation in gastric cancer (Figure $2 \mathrm{~A}$ ). Alteration frequency of CD44 mutation in colon and gastric cancer was analyzed by using BioPortal. Less than $2 \%$ mutation in the patients with colon and gastric cancer was observed (Figure 2B).

\section{CD44 mRNA in colon and gastric cancer tissues}

The expression profile of CD44 was found by using the SAGE Digital Gene Expression Display. Higher levels of CD44 mRNA are mainly in brain, stomach, pancreas, liver, and colon cancer tissues, compared with their matched normal tissues (Figure 3). Oncomine analysis of cancer vs. normal tissue showed that CD44 mRNA was significantly higher in colon adenocarcinoma, colon mucinous adenocarcinoma, diffuse gastric adenocarcinoma, gastric intestinal type adenocarcinoma, gastric mixed adenocarcinoma (Figure 4). Kaplan-Meier analysis revealed that high CD44 mRNA was correlated with a benign survival rate in gastric cancer $(P=0.011)$, while the opposite role of CD44 mRNA was observed in colon cancer $(P=0.005)$ (Figure 4$)$. In addition, we analyzed the prognostic roles of CD44 mRNA in subtypes of gastric cancer. High level of CD44 mRNA could improve the survival rate in the patients with intestinal-type gastric cancer $(P=0.035)$ (Supplementary Figure S2). Just the opposite role was observed in the patients with diffuse-type gastric cancer $(P=0.0064)$ (Supplementary Figure S2). No influence of CD44 mRNA on mixed-type gastric cancer was found ( $P=0.14$, Supplementary Figure S2). Opposite roles of CD44 mRNA were also found in welldifferentiated gastric cancer and poorly/moderately differentiated gastric cancer (Supplementary Figure S2).

\section{Coexpression of CD44 mRNA}

Coexpression genes of CD44 were shown in Figure 5A. Among these genes, we focused on CD4 and CD74. Figure 5B illustrated the whole view for CD44, CD4, and CD74 mRNA of colon and gastric cancer samples based on TCGA database. The heatmaps of CD44 mRNA in colon cancer were strikingly opposite to CD4 and CD74 (Figure 5B). However, no obvious trend was found among CD44, CD4, and CD74 mRNA in gastric cancer (Figure 5B).

\section{DISCUSSION}

Many studies have shown the association of CD44 polymorphisms with cancer risk prediction and prognosis [12-16]. CD44 rs187115 was associated with an increased risk of tumor-related death and lower drug sensitivity in sarcoma [13]. CD44 rs187115 is also correlated with bone metastasis and tumor stage in non small cell lung cancer (NSCLC) patients [14]. Although CD44 polymorphism is very important for cancers, few reports showed the roles of CD44 polymorphism in colon and gastric cancer. CD44 rs8193 is an independent prognostic marker for high-risk stage II and stage III colon cancer patients [15]. CD44 rs187116 could predict disease recurrence in gastric cancer patients, and the single nucleotide polymorphism (SNP) was associated with CD44 isoform switching [16]. In this study, based on the results of bioinformatic analyses, we speculated there may be two reasons for a few studies on CD44 polymorphism in colon and gastric cancer. One reason is that the major proportion of mutation in these two cancers is synonymous mutations. Another reason is that low alteration frequency was observed in colon and gastric cancer.

In our study, higher CD44 mRNA was identified in both colon and gastric cancer by using TCGA database. This finding was consistent with previous studies. Jing et al. [17] found that CD44 mRNA was increased in colorectal cancer tissues than that in matched normal tissues. Wang et al. [18] performed a quantitative review and confirmed higher CD44 levels in gastric cancer. Furthermore, we found that CD44 mRNA is associated with poor overall survival (OS) in colon cancer, while with begin OS in gastric cancer. However, the prognostic roles of CD44 protein in colon and gastric cancer remain controversial. Both Lugli et al. [19] and Hong et al. [20] found that loss of membranous CD44 was linked to the worse survival in colorectal cancer. In the Pitule's study, no relation was found between CD44 expression and OS of colorectal cancer patients [21]. Huh et al. [22] found that CD44 overexpression is an independent unfavorable prognostic factor for OS in colorectal cancer. Similar controversies also existed in gastric cancer [23-25]. The reason for these controversies is very complex. First of all, the heterogeneity of CD44 protein varies in different cell types and growth conditions $[7,8]$. So, the protein sequence with immunogen is different in each cancer cell (Supplementary Figure S1). Second, it is difficult to make a definite conclusion for the limited sample size of a single study. Based on the reasons above, it seems that CD44 mRNA used as a prognostic marker is better than CD44 protein.

Another finding in this study is that CD4 and CD74 may be used as markers to predict the prognosis of colon and gastric cancer, but not the markers for cancer stem cell. $\mathrm{CD}^{+} \mathrm{T}$ cell-dependent anti-tumor immunity is the immunological driver behind beneficial clinical responses to cancer [26]. In this study, we confirmed CD44 was strikingly opposite to CD4 in colon cancer. It indicated that CD44 expression may regulate antitumor immunity by suppressing CD4 expression. CD74, a transmembrane glycoprotein, associates with the major histocompatibility complex (MHC) Class II 

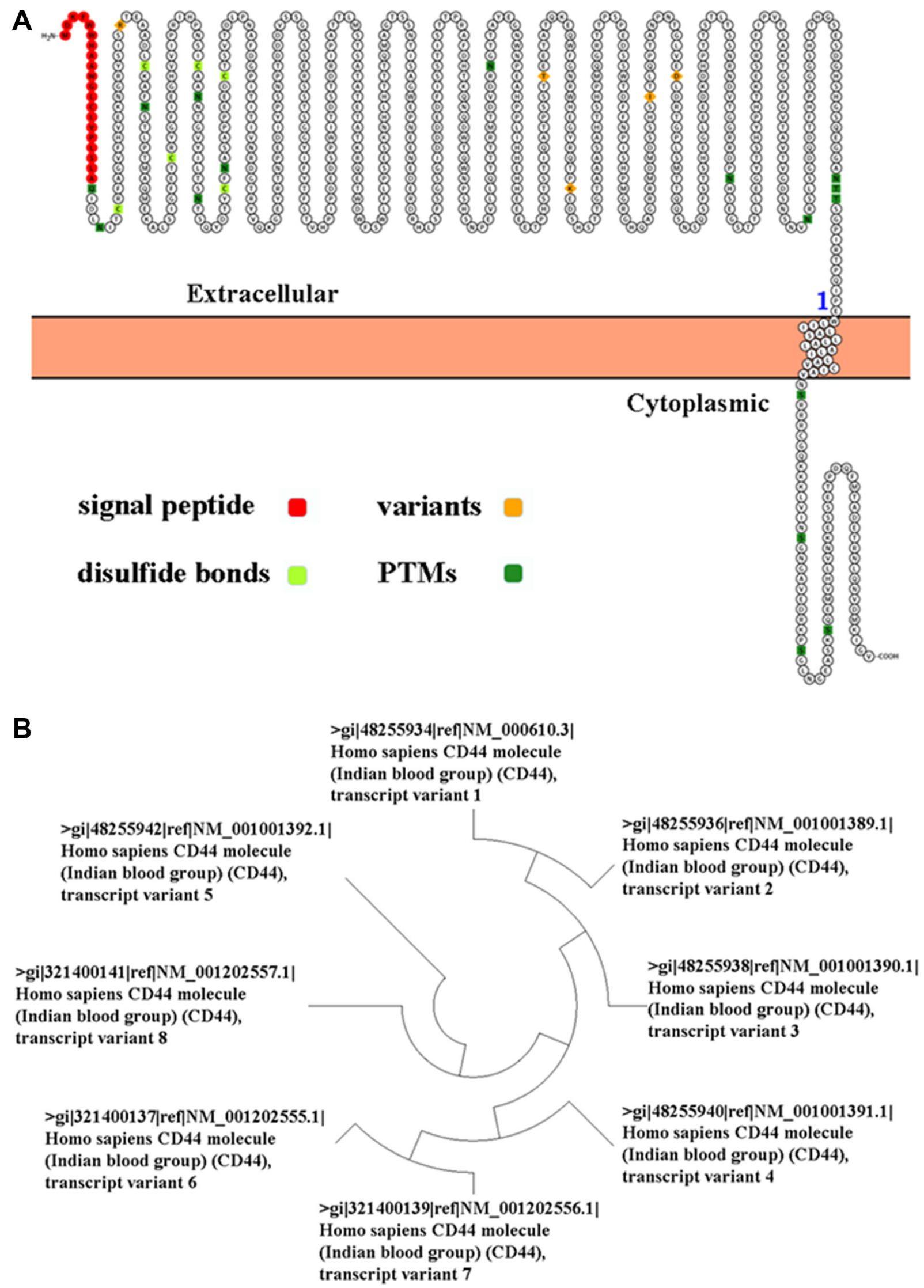

Figure 1: (A) Ideograph of CD44 protein was generated by using Peptide Atlas. (B) An evolutionary tree of CD44 transcript variant was generated by the maximum likelihood analysis. 


\section{A colon cancer}

\begin{tabular}{|c|c|c|c|}
\hline Color & Mutation Type & $\begin{array}{l}\text { Mutant } \\
\text { samples }\end{array}$ & Percentage \\
\hline & $\begin{array}{l}\text { Substitution } \\
\text { nonsense }\end{array}$ & 0 & 0.00 \\
\hline & $\begin{array}{l}\text { Substitution } \\
\text { missense }\end{array}$ & 7 & 63.64 \\
\hline & $\begin{array}{l}\text { Substitution } \\
\text { synonymous }\end{array}$ & 4 & 36.36 \\
\hline & Insertion inframe & 0 & 0.00 \\
\hline & Insertion frameshift & 0 & 0.00 \\
\hline & Deletion inframe & 0 & 0.00 \\
\hline & Deletion frameshift & 0 & 0.00 \\
\hline & Complex & 0 & 0.00 \\
\hline & Other & 0 & 0.00 \\
\hline & Total & 11 & 100 \\
\hline
\end{tabular}

\begin{tabular}{llll} 
Color & Mutation Type & Mutant samples & Percentage \\
\hline$A>C$ & 0 & 0.00 \\
$A>G$ & 1 & 9.09 \\
$A>T$ & 0 & 0.00 \\
$C>A$ & 0 & 0.00 \\
$C>T$ & 4 & 36.36 \\
$C>G$ & 0 & 0.00 \\
$G>A$ & 4 & 36.36 \\
$G>C$ & 0 & 0.00 \\
$G>T$ & 0 & 0.00 \\
$T>A$ & 0 & 0.00 \\
$T>C$ & 1 & 9.09 \\
$T>G$ & 1 & 9.09 \\
Total & 11 & 100
\end{tabular}

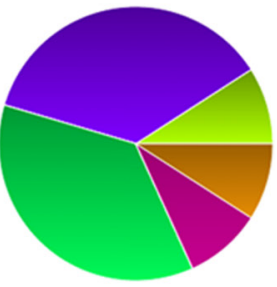

gastric cancer

\begin{tabular}{llll} 
Color & Mutation Type & $\begin{array}{l}\text { Mutant } \\
\text { samples }\end{array}$ & Percentage \\
\hline $\begin{array}{l}\text { Substitution } \\
\text { nonsense } \\
\frac{\text { Substitution }}{\text { missense }}\end{array}$ & 0 & 0.00 \\
$\begin{array}{l}\text { Substitution } \\
\text { Synonvmous }\end{array}$ & 4 & 52.94 \\
\hline $\begin{array}{l}\text { Insertion inframe } \\
\text { Insertion frameshift }\end{array}$ & 0 & 23.53 \\
\hline $\begin{array}{l}\text { Deletion inframe } \\
\text { Deletion frameshift }\end{array}$ & 0 & 0.00 \\
\hline Complex & 0 & 0.00 \\
Other & 0 & 0.00 \\
\hline Total & 17 & 11.76 \\
& 0.00 \\
\hline
\end{tabular}

\begin{tabular}{llll} 
Color & Mutation Type & Mutant samples & Percentage \\
\hline$A>C$ & 1 & 7.69 \\
$A>G$ & 0 & 0.00 \\
$A>T$ & 1 & 7.69 \\
$C>A$ & 0 & 0.00 \\
$C>T$ & 3 & 23.08 \\
$C>G$ & 0 & 0.00 \\
$G>A$ & 1 & 7.69 \\
$G>C$ & 2 & 15.38 \\
$G>T$ & 0 & 0.00 \\
$T>A$ & 0 & 0.00 \\
$I>C$ & 3 & 23.08 \\
$I>G$ & 2 & 15.38 \\
$I>t a l$ & 13 & 100
\end{tabular}

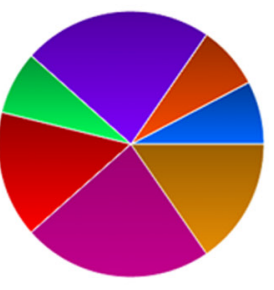

B

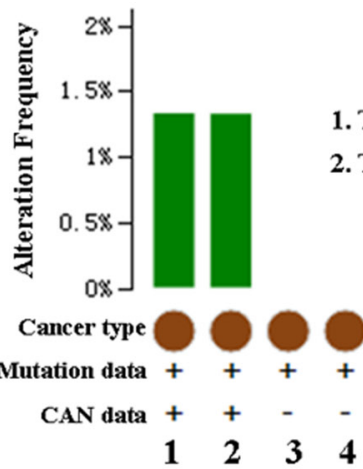

1. TCGA, Provisional 3. Genentech, Nature 2012

2. TCGA, Nature 2012 4. MSKCC, Genome Biology 2014
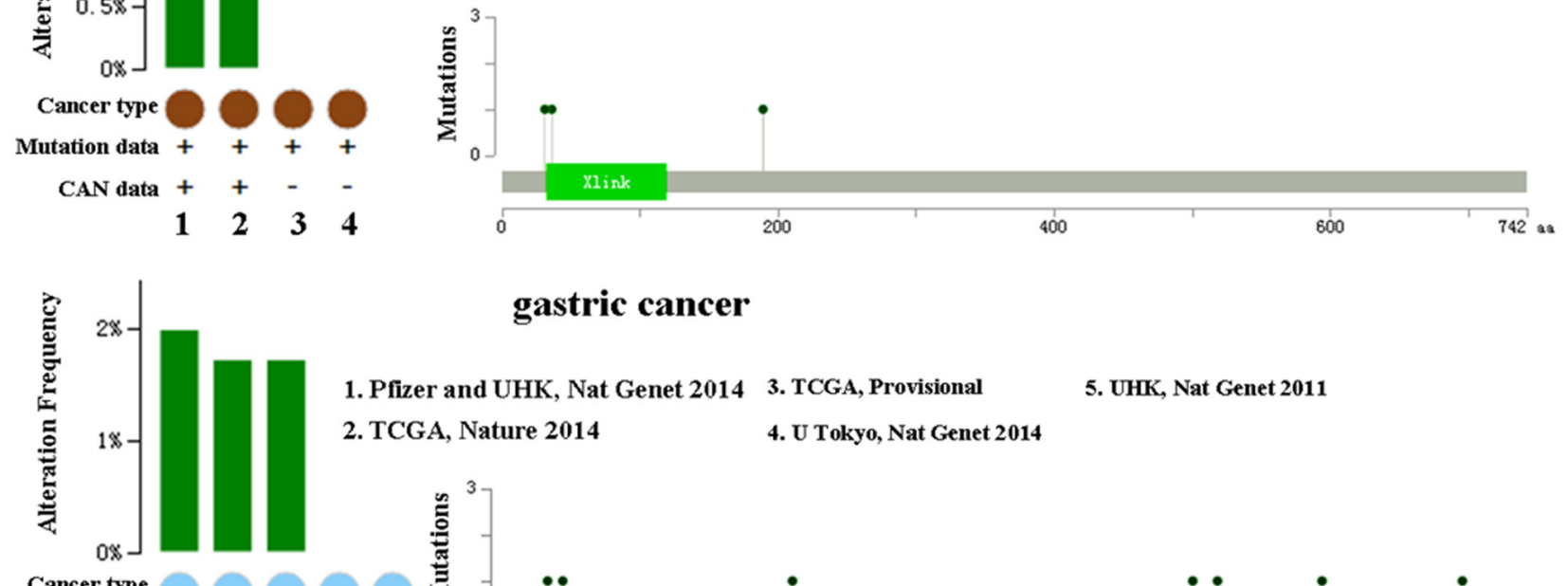

gastric cancer

1. Pfizer and UHK, Nat Genet 2014 3. TCGA, Provisional

5. UHK, Nat Genet 2011

2. TCGA, Nature 2014 4. U Tokyo, Nat Genet 2014

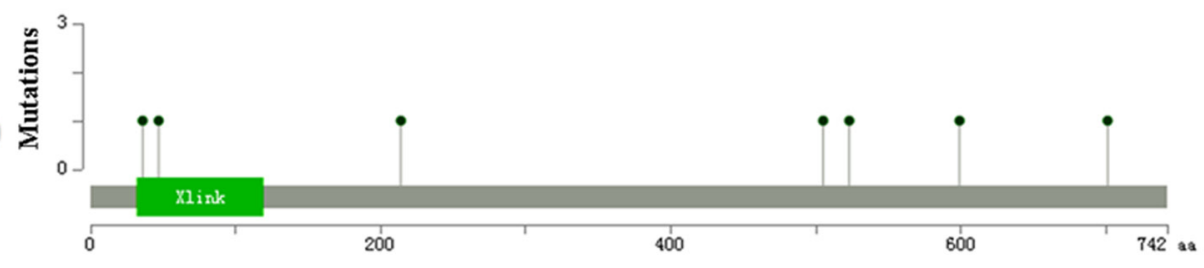

Figure 2: (A) Pie-chart showed the percentage of the mutation type of CD44 in colon and gastric cancer according to COSMIC database. (B) Alteration frequency of CD44 mutation in colon and gastric cancer was analyzed by using BioPortal. 
SAGE Anatomic Viewer Results

N口RMAL

CANCER

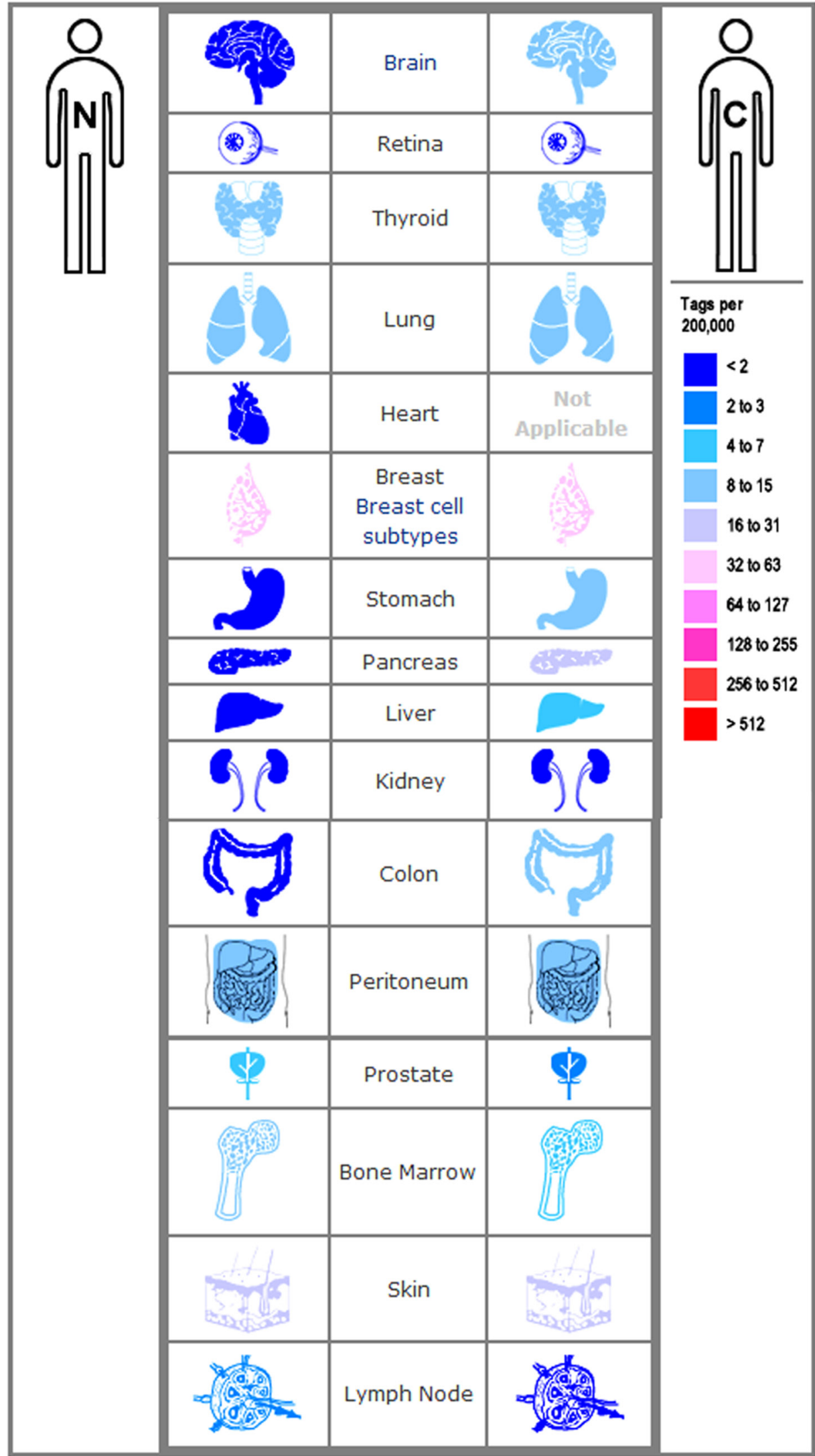

Figure 3: Expression profile for CD44 in human cancers found by the SAGE DGED. 

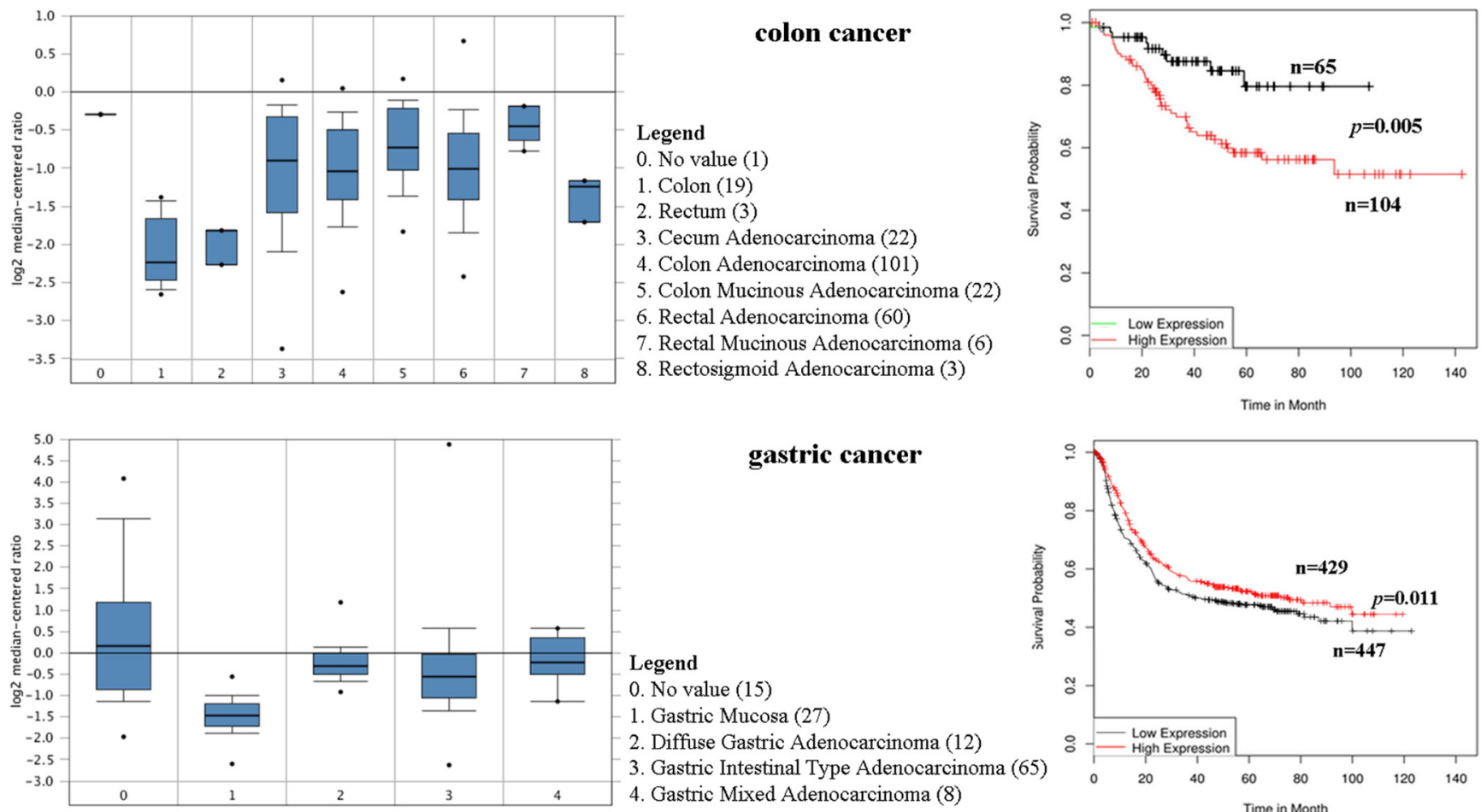

Legend

0 . No value (15)

1. Gastric Mucosa (27)

2. Diffuse Gastric Adenocarcinoma (12)

3. Gastric Intestinal Type Adenocarcinoma (65)

4. Gastric Mixed Adenocarcinoma (8)

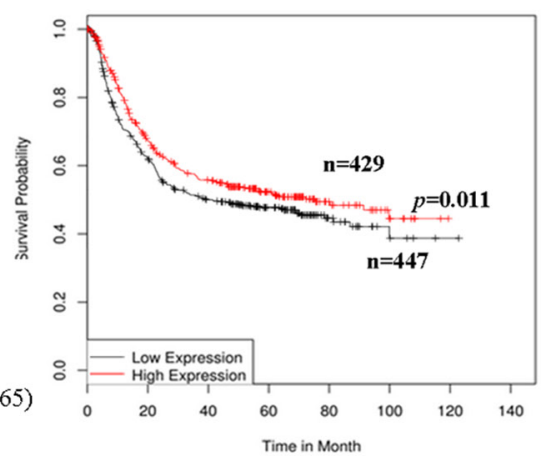

Figure 4: CD44 mRNA was evaluated in colon and gastric cancer by using Oncomine analysis. Prognostic significance of CD44 enriched in colon and gastric cancer.
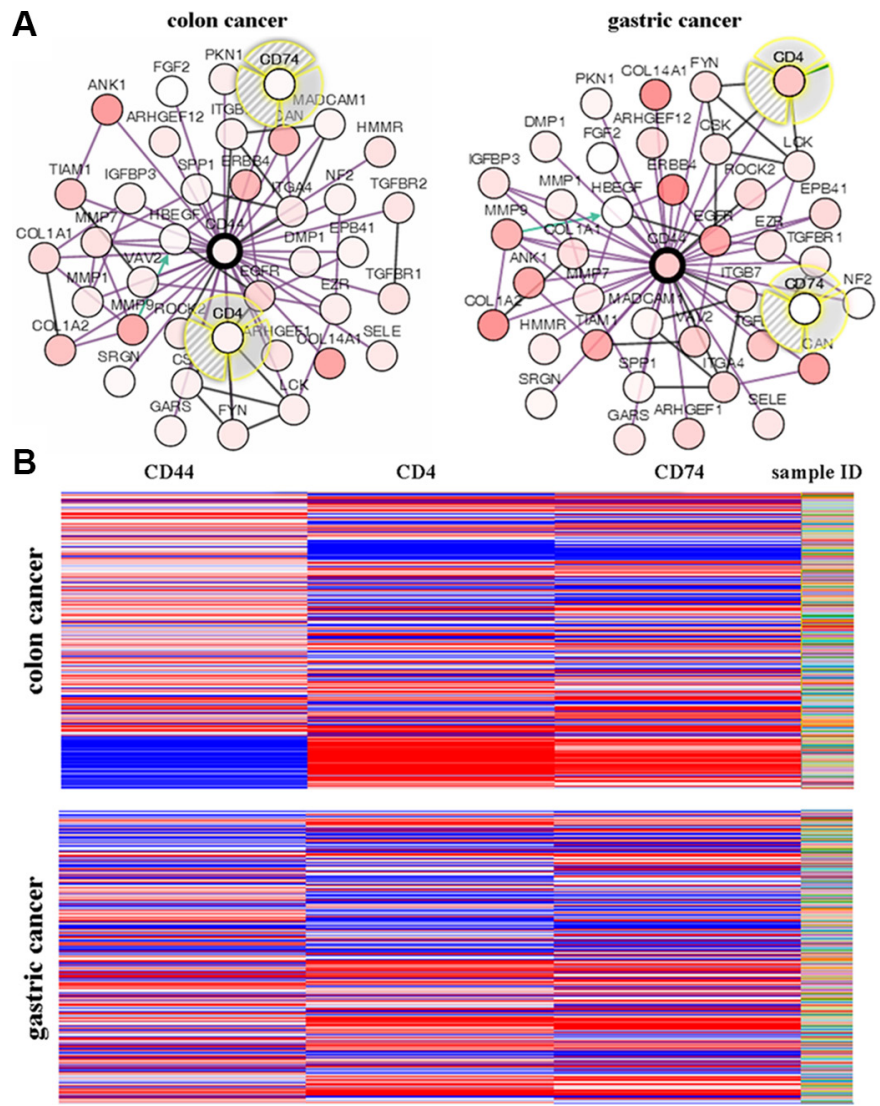

Figure 5: (A) Interaction genes of CD44 were analyzed by using Oncomine. (B) Relationships of CD44, CD4 and CD74 in colon and gastric cancer were analyzed by using the UCSC Cancer Genomics Browser. 
and plays important roles in the intratumoral immune response [27-29]. CD74 was overexpressed in thyroid malignancy, malignant pleural mesothelioma, and head and neck squamous cell carcinomas, and it is associated with advanced tumor stage [30-32]. Shakib et al. [33] found that both CD44 and CD74 proteins were significantly overexpressed in oral squamous cell carcinoma (OSCC) patients. These results indicated that CD4 and CD74 were not expressed in CD44 ${ }^{+}$cancer stem-like cells, and their expression in immune cells is regulated by $\mathrm{CD} 44$ induced-antitumor immune response. However, further studies are required to confirm the roles of CD4 and CD74 in cancers.

There are three main conclusions in this study: 1) Low alteration frequency was observed in colon and gastric cancer; 2) High CD44 mRNA was found in colon and gastric cancer than that in matched normal tissues, and it correlated with a benign survival rate in gastric cancer; 3) CD4 and CD74 may be used as markers to predict the prognosis of colon and gastric cancer, but not the markers for cancer stem cell. However, further studies have to be performed in the future.

\section{MATERIALS AND METHODS}

\section{Phylogenetic analysis}

Maximum likelihood (ML), neighbor-joining (NJ), and Bayesian Markov chain Monte Carlo (MCMC) approaches were used to determine the phylogenetic relationships of CD44 transcript variant 1-8. Evolutionary tree was generated by using the MEGA 5.1 software.

\section{COSMIC analysis for CD44 mutations}

The Catalog of Somatic Mutations in Cancer (COSMIC) database (http://www.sanger.ac.uk/cosmic/) was used for analysis CD44 mutations. Pie charts were generated for a distribution overview and substitutions on the coding strand in colon cancer and gastric cancer.

\section{cBioPortal analysis for alteration frequency of CD44}

Alteration frequency of CD44 mRNA in colorectal adenocarcinoma and stomach adenocarcinoma was performed using BioPortal for Cancer Genomics (http:// www.cbioportal.org). All searches were performed according to the cBioPortal's online instructions. The database query was based on mutation and altered expression of the CD44 in colorectal adenocarcinoma (TCGA, Provisional; TCGA, Nature 2012; Genentech, Nature 2012; MSKCC, Genome Biology 2014) and stomach adenocarcinoma (Pfizer and UHK, Nat Genet 2014; TCGA, Nature 2014 TCGA, Provisional; U Tokyo, Nat Genet 2014; UHK, Nat Genet 2011).

\section{Serial analysis of gene expression (SAGE)}

All available published SAGE data were used for analysis of CD44 gene expression in normal and cancerous tissues. Digital CD44 gene expression profiles were analyzed using SAGE Genie tools (http://www.ncbi. nlm.nih.gov/SAGE/).

\section{Oncomine database analysis}

CD44 mRNA levels in colon and gastric cancer tissues were compared with their matched normal tissues by using TCGA datasets in Oncomine database (http:// www.oncomine.org). The threshold used to obtain the most significant probes of the queried gene for each microarray data included a two-fold difference in expression between cancers and normal tissues with a $P$-value $<1 \times 10^{-4}$. Genes coexpressed with CD44 were also analyzed and the map was generated by using Cytoscape 3.3.0.

\section{Kaplan-Meier plotter analysis}

The prognostic value of CD44 gene in colon cancer and gastric cancer was analyzed using Kaplan-Meier Plotter (http://kmplot.com/analysis/) and PPISURV (http:// www.bioprofiling.de). Overall survival of the patient with high and low levels of CD44 was shown by using a Kaplan-Meier survival plot.

\section{Genomic data and views}

The UCSC Cancer Genomics Browser (https:// genome-cancer.ucsc.edu/) was used for integrative visualization of large, complex genomic datasets. According to the cluster results of Oncomine database analysis, we entered CD44, CD4, and CD74 into the search box to perform a search by using Genes viewing mode.

\section{CONFLICTS OF INTEREST}

The authors declare that they have no competing interests.

\section{FUNDING}

This study was supported by National Natural Scientific Foundation of China (No.81572777 and No.81502558) and Talents Introduction Projects of Liaoning Medical University.

\section{REFERENCES}

1. Chen W, Zheng R, Baade PD, Zhang S, Zeng H, Bray F, Jemal A, Yu XQ, He J. Cancer statistics in China, 2015. CA Cancer J Clin. 2016; 66:115-32. 
2. Avgustinova A, Benitah SA. The epigenetics of tumour initiation: cancer stem cells and their chromatin. Curr Opin Genet Dev. 2016; 36:8-15.

3. Zöller M. CD44: can a cancer-initiating cell profit from an abundantly expressed molecule? Nat Rev Cancer. 2011; 11:254-67.

4. Screaton GR, Cáceres JF, Mayeda A, Bell MV, Plebanski M, Jackson DG, Bell JI, Krainer AR. Identification and characterization of three members of the human SR family of pre-mRNA splicing factors. EMBO J. 1995; 14:4336-49.

5. Naor D, Sionov RV, Ish-Shalom D. CD44: structure, function, and association with the malignant process. Adv Cancer Res. 1997; 71:241-319.

6. Chanmee T, Ontong P, Kimata K, Itano N. Key Roles of Hyaluronan and Its CD44 Receptor in the Stemness and Survival of Cancer Stem Cells. Front Oncol. 2015; 5:180.

7. Zeilstra J, Joosten SP, van Andel H, Tolg C, Berns A, Snoek M, van de Wetering M, Spaargaren M, Clevers H, Pals ST. Stem cell CD44v isoforms promote intestinal cancer formation in Apc(min) mice downstream of Wnt signaling. Oncogene. 2014; 33:665-70.

8. Fox SB, Fawcett J, Jackson DG, Collins I, Gatter KC, Harris AL, Gearing A, Simmons DL. Normal human tissues, in addition to some tumors, express multiple different CD44 isoforms. Cancer Res. 1994; 54:4539-46.

9. Robbins EW, Travanty EA, Yang K, Iczkowski KA. MAP kinase pathways and calcitonin influence CD44 alternate isoform expression in prostate cancer cells. BMC Cancer. 2008; 8:260.

10. Zhao LH, Lin QL, Wei J, Huai YL, Wang KJ, Yan HY. CD44v6 expression in patients with stage II or stage III sporadic colorectal cancer is superior to CD44 expression for predicting progression. Int J Clin Exp Pathol. 2015; 8:692-701.

11. Wu Y, Li Z, Zhang C, Yu K, Teng Z, Zheng G, Wang S, Liu Y, Cui L, Yu X. CD44 family proteins in gastric cancer: a meta-analysis and narrative review. Int J Clin Exp Med. 2015; 8:3595-606.

12. Chou YE, Hsieh MJ, Hsin $\mathrm{CH}$, Chiang WL, Lai YC, Lee YH, Huang SC, Yang SF, Lin CW. CD44 gene polymorphisms and environmental factors on oral cancer susceptibility in Taiwan. PLoS One. 2014; 9: e93692.

13. Vazquez A, Grochola LF, Bond EE Levine AJ, Taubert H, Müller TH, Würl P, Bond GL. Chemosensitivity profiles identify polymorphisms in the p53 network genes 14-33 tau and CD44 that affect sarcoma incidence and survival. Cancer Res. 2010; 70:172-80

14. Liu Y, Qing H, Su X, Wang C, Li Z, Liu S. Association of CD44 Gene Polymorphism with Survival of NSCLC and Risk of Bone Metastasis. Med Sci Monit. 2015; 21:2694-700.

15. Gerger A, Zhang W, Yang D, Bohanes P, Ning Y, Winder T, LaBonte MJ, Wilson PM, Benhaim L, Paez D, El-Khoueiry R, El-Khoueiry A, Kahn M, Lenz HJ. Common cancer stem cell gene variants predict colon cancer recurrence. Clin Cancer Res. 2011; 17:6934-43.
16. Suenaga M, Yamada S, Fuchs BC, Fujii T, Kanda M, Tanaka C, Kobayashi D, Fujiwara M, Tanabe KK, Kodera Y. CD44 single nucleotide polymorphism and isoform switching may predict gastric cancer recurrence. J Surg Oncol. 2015; 112:622-8.

17. Jing F, Kim HJ, Kim CH, Kim YJ, Lee JH, Kim HR. Colon cancer stem cell markers CD44 and CD133 in patients with colorectal cancer and synchronous hepatic metastases. Int $\mathrm{J}$ Oncol. 2015; 46:1582-8.

18. Wang W, Dong LP, Zhang N, Zhao CH. Role of cancer stem cell marker CD44 in gastric cancer: a meta-analysis Int J Clin Exp Med. 2014; 7:5059-66.

19. Lugli A, Iezzi G, Hostettler I, Muraro MG, Mele V, Tornillo L, Carafa V, Spagnoli G, Terracciano L, Zlobec I. Prognostic impact of the expression of putative cancer stem cell markers CD133, CD166, CD44s, EpCAM, and ALDH1 in colorectal cancer. Br J Cancer. 2010; 103:382-90.

20. Hong I, Hong SW, Chang YG, Lee WY, Lee B, Kang YK, Kim YS, Paik IW, Lee H. Expression of the cancer stem cell markers CD44 and CD133 in colorectal cancer: An immunohistochemical staining analysis. Ann Coloproctol. 2015; 31:84-91.

21. Pitule P, Cedikova M, Daum O, Vojtisek J, Vycital O, Hosek P, Treska V, Hes O, Kralickova M, Liska V. Immunohistochemical detection of cancer stem cell related markers CD44 and CD133 in metastatic colorectal cancer patients. Biomed Res Int. 2014; 2014:432139.

22. Huh JW, Kim HR, Kim YJ, Lee JH, Park YS, Cho SH, Joo JK. Expression of standard CD44 in human colorectal carcinoma: association with prognosis. Pathol Int. 2009; 59:241-6.

23. Setälä L, Lipponen P, Tammi R, Tammi M, Eskelinen M, Alhava E, Kosma VM. Expression of CD44 and its variant isoform v3 has no prognostic value in gastric cancer. Histopathology. 2001; 138:13-20.

24. Chen S, Hou JH, Feng XY, Zhang XS, Zhou ZW, Yun JP, Chen YB, Cai MY. Clinicopathologic significance of putative stem cell marker, CD44 and CD133, in human gastric carcinoma. Surg Oncol. 2013; 107:799-806.

25. Xie JW, Huang CM, Zheng CH, Li P, Wang JB, Lin JX, $\mathrm{Lu}$ J. Expression tumor stem cell surface marker CD44 in gastric cancer and its significance [Article in Chinese]. Zhonghua Wei Chang Wai Ke Za Zhi. 2013; 16:1107-12.

26. Guy TV, Terry AM, Bolton HA, Hancock DG, Zhu E, Brink R, McGuire HM, Shklovskaya E, Fazekas de St Groth B. Collaboration between tumor-specific CD4+ T cells and B cells in anti-cancer immunity. Oncotarget. 2016; 7:30211-29. doi: 10.18632/oncotarget.8797.

27. Borghese F, Clanchy FI. CD74: an emerging opportunity as a therapeutic target in cancer and autoimmune disease. Expert Opin Ther Targets. 2011; 15:237-251.

28. Wilkinson RDA, Magorrian SM, Williams R, Young A, Small DM, Scott CJ, Burden RE. CCL2 is transcriptionally controlled by the lysosomal protease cathepsin S in a CD74- 
dependent manner. Oncotarget. 2015; 6:29725-39. doi: 10.18632/oncotarget.5065.

29. Wang ZQ, Milne K, Webb JR, Watson PH. CD74 and intratumoral immune response in breast cancer. Oncotarget. 2016. doi: 10.18632/oncotarget.8610. [Epub ahead of print].

30. Cheng SP, Liu CL, Chen MJ, Chien MN, Leung CH, Lin $\mathrm{CH}$, Hsu YC, Lee JJ. CD74 expression and its therapeutic potential in thyroid carcinoma. Endocr Relat Cancer. 2015; 22:179-90.

31. Kindt N, Lechien JR, Nonclercq D, Laurent G, Saussez S. Involvement of CD74 in head and neck squamous cell carcinomas. J Cancer Res Clin Oncol. 2014; 140:937-47.
32. Otterstrom C, Soltermann A, Opitz I, Felley-Bosco E, Weder W, Stahel RA, Triponez F, Robert JH, SerreBeinier V. CD74: a new prognostic factor for patients with malignant pleural mesothelioma. Br J Cancer. 2014; 110:2040-6.

33. Shakib PA, Ensani F, Abdirad A, Valizadeh B, Seyedmajidi M, Sum S. CD44 and CD74: The promising candidates for molecular targeted therapy in oral squamous cell carcinoma. Dent Res J (Isfahan). 2015; 12:181-6. 